RAD Conference Proceedings, vol. 4, pp. 90-94, 2020

ISSN 2466-4626 (online) | DOI: 10.21175/RadProc.2020.19

www.rad-proceedings.org

\title{
FREE FATTY ACIDS AND HEPATIC ACTIVITY IN TYPE 2 DIABETES
}

\author{
Šaćira Mandal ${ }^{*}$ \\ University of Sarajevo, Faculty of Pharmacy, Sarajevo, Bosnia and Herzegovina
}

\begin{abstract}
Metabolic derangements in Type 2 diabetes mellitus (T2D) are associated primarily with the carbohydrate and lipid levels disturbances. Increased flow of free fatty acids (FFAs) into the blood that is coming from the adipocytes as well as an elevated flux of FFAs from de novo lipid synthesis in the liver contribute to these metabolic disturbances. Previous studies suggested a strong association of the hepatic activity of certain enzymes, such as aspartate and alanine transferase (AST, ALT), gamma glutamyl transpeptidase (GGT), and alkaline phosphatase $(A L P)$ with the progression of T2D. In this study, the potential association of the hepatic activities of the liver enzymes and FFAs levels in T2D was examined. Analysis of the activities of ALT, AST, GGT and AP, as well levels of FFAs, fasting plasma glucose (FPG), and lipid profile was performed in 40 healthy control and 71 diabetic subjects. All participants were free of hepatitis, viral infections or active liver damage. The results showed a positive association between levels of palmitic and oleic acids with ALT activity $(p<0.05)$, while the activity of GGT was significantly associated with the levels of palmitic, stearic, and oleic fatty acids $(p<0.01)$. Interestingly, in control group, a positive correlation was found between palmitoleic acid levels with ALT activity $(p<0.05)$, and a negative correlation palmitoleic acid with ALP activity $(p<0.05)$ was observed. Obtained data suggest that an elevation of free fatty acid levels and the hepatic fat accumulation in insulin-resistant conditions affect the hepatic enzymes activities, which might contribute further to the progression of Type 2 diabetes and its complications.
\end{abstract}

Keywords: Free fatty acids, hepatic enzymes, Type 2 diabetes

\section{INTRODUCTION}

Type 2 diabetes mellitus (T2DM) is one of the most prevalent chronic metabolic diseases around the world, with an increase in its prevalence due to genetic and environmental risk factors. According to International Diabetes Federation (IDF) more than 600 million world population will be affected till 2035. Metabolic derangements in T2D are associated primarily with the carbohydrate and lipid pathway metabolisms disturbances [1].

Previous studies reported that circulating concentrations of free fatty acids (FFAs) from adipose tissue have been proposed to be a possible link between abdominal obesity, insulin resistance (IR) metabolic syndrome (MetS), increased risk of T2D, and other obesity-related metabolic disorders [2]. Insulin resistant adipocytes release high concentration of FFAs to blood which promotes lipid accumulation and IR in key organs (e.g., liver, pancreas, heart, and skeletal muscle) and results in whole body-metabolic alterations [3, 4]. Increased flow of FFAs into the blood that is coming from the adipocytes as well as an elevated flux of FFAs from de novo lipid (DNL) synthesis in the liver contribute to accumulation of fat and hepatic insulin resistance [5-7].

The liver is a major organ that has a key role in carbohydrate, lipid and protein metabolisms. In clinical practice, measurement of the activity of specific liver enzymes, such as aspartate and alanine transferase (AST, ALT), gamma glutamyl transpeptidase (GGT), and alkaline phosphatase (ALP) demonstrate the liver function $[8,9]$. Several investigations have been observed the association of elevated serum hepatic enzyme levels with developing of T2D. Also, studies suggested a strong predictive function of the liver enzymes as independent markers with the progression of T2D [10-12].

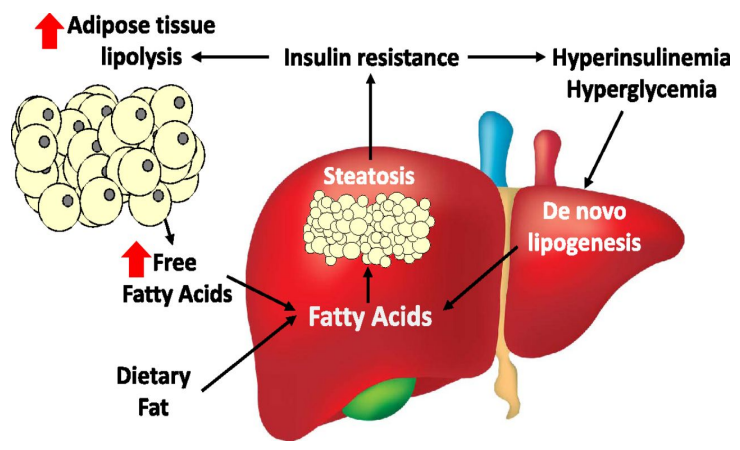

Figure 1. Increased release of free fatty acids by adipose tissue and hyperglycemia/hyperinsulinemia, which promotes hepatic de novo lipogenesis (DNL).

Furthermore, fat accumulation with both elevated FFAs and liver enzymes activity lead to nonalcoholic fatty liver disease (NAFLD) as the most common liver disease and disorder. Recent epidemiological

* mandalshakira@yahoo.co.uk 
Š. Mandal, Free fatty acids and hepatic activity in Type 2 diabetes, RAD Conf. Proc., vol. 4, 2020, 90-94

investigations reported that T2D patients have a twofold higher risk for development of NAFLD and vice versa; the prevalence of NAFLD among patients with T2D is about $80 \%$ [13].

The diagnosis of NAFLD in patients with or without T2D according to recommendation of the $\mathrm{ADA}$ is elevated ALT or nonalcoholic fatty liver (NAFL). The identification and detection of NAFLD performed by standard imaging techniques, such as ultrasonography (USG), computed tomography (CT), and magnetic resonance imaging (MRI) or the gold standard method - liver biopsy. However, these methods are insensitive, time-consuming, expensive and invasive with seriously consequences for patients, and in routine clinical laboratory often are not appropriate. Therefore, a multidisciplinary approach needed to identify T2D patients at risk for developing of NAFLD, using sensitive, accurate, reliable and cost-effective analytical tool $[14,15]$.

In this study, the potential association of the activities of the liver enzymes and free fatty acids levels in T2D patients was examined.

\section{EXPERIMENTAL}

\subsection{Subjects}

The study included 111 participants: 71 patients with T2D, and 40 healthy controls of both gender, aged from 35 up to 65 years. T2D was diagnosed by endocrinologists and diabetologists according to definitions of American Diabetes Assotion (ADA) [16]. Diabetic patients and healthy subjects were recruited at the Department of Internal Medicine, General Hospital in Tešanj. Patients treated with insulin, lipid-lowering drugs and patients with acute and chronic kidney disease, endocrine disorders, acute infection and/or inflammation and hormonal therapy were excluded. Individuals in control group were not taking any medication during of the study. The research was approved by the Hospital Ethics Committee and was performed in accordance with the Helsinki Declaration - Ethical Principles for Medical Research Involving Human Subjects (initiated June 1964, last amended October 2000) and each patient has given a written informed consent [17].

\subsection{Biochemical analyses}

Fasting whole blood samples were obtained from an antecubital vein and blood samples were left for 20 minutes at room temperature, and centrifuged at 3000 rpm for 4 to 5 minutes. Serum levels of fasting glucose, triglycerides (TG), total cholesterol (TC), high-density lipoprotein cholesterol (HDL-cholesterol), low-density lipoprotein cholesterol (LDL-cholesterol), glycated hemoglobin (HbA1c), liver enzyme activities alanine aminotransferase, aspartate aminotransferase, $\gamma$ glutamyl transpeptidase and alkaline phosphatase (ALT, AST, GGT and ALP) were determined by using VITROS auto analyzer 350 Chemistry System (OrthoClinical Diagnostics, Rochester, New York, USA).For analysis of all biochemical parameters, IFCC
(International Federation of Clinical Chemistry and Laboratory Medicine) standard protocols were used.

\subsection{Sample preparation}

Preparation of samples for fatty acid analysis was done by methylation of serum samples, followed by conversion of FFAs to corresponding fatty acid methyl esters [15]. Fourteen FFAs with medium and longchain length, i.e. from $\mathrm{C}_{14}$ to $\mathrm{C} 22$ carbon atoms with different degree of unsaturation, in serum of T2D, and nondiabetic subjects were analyzed on a Shimadzu QP-5000 GC/MS gas chromatograph equipped with mass spectrometer detector (Shimadzu, Tokyo, Japan). The identification of each fatty acid peak was obtained by comparing the retention time of the peak with the retention times of referent standards with known fatty acids composition, and heptadecanoic acid $\mathrm{C} 17: 0$ as internal standard was used for calculation the concentration of individual FFAs.

Statistical analysis was done using SPSS 17.0 for Windows (SPSS, Chicago, IL, USA). Data are presented as the mean \pm standard deviation when data were found to be normally distributed or as the median if the distribution was skewed. Differences between groups were analyzed using the Student's $t$-test or the Mann-Whitney U test. Spearman correlation analysis was used to examine the correlation between serum FFA levels and biochemical and laboratory parameters. Statistical significance was set as $\mathrm{P}<0.05$.

\section{RESULTS AND DISCUSSION}

The biochemical characteristics of study participants are presented in Table 1. Values of all the measured traits were significantly different between cases and controls.

Table 1. Biochemical characteristics in study populations

\begin{tabular}{|l|c|c|c|}
\hline \multicolumn{1}{|c|}{ Parameter } & $\begin{array}{c}\text { Cases } \\
\text { N=71 }\end{array}$ & $\begin{array}{c}\text { Controls } \\
\text { N=40 }\end{array}$ & $\begin{array}{c}\boldsymbol{p} \\
\text { value }\end{array}$ \\
\hline Age, years & $61(37-87)$ & $43(23-62)$ & 0.000 \\
\hline $\begin{array}{l}\text { Glucose, } \\
\text { mmol/L }\end{array}$ & $\begin{array}{c}9 \cdot 53 \\
(4.97-16.60)\end{array}$ & $\begin{array}{c}5.26 \\
(4.10-6.50)\end{array}$ & 0.000 \\
\hline $\begin{array}{l}\text { Total } \\
\text { Cholesterol, } \\
\text { mmol/L }\end{array}$ & $\begin{array}{c}5 \cdot 51 \\
(3.83-10.90)\end{array}$ & $\begin{array}{c}5 \cdot 77 \\
(3 \cdot 30-8.00)\end{array}$ & 0.000 \\
\hline $\begin{array}{l}\text { Triglyceride, } \\
\text { mmol/L }\end{array}$ & $\begin{array}{c}5 \cdot 77 \\
(3.30-8.00)\end{array}$ & $\begin{array}{c}2.63 \\
(0.46-12.06)\end{array}$ & 0.000 \\
\hline AST, U/L & $32(18-62)$ & $29(13-125)$ & 0.000 \\
\hline ALT, U/L & $37(17-125$ & $31(12-125)$ & 0.000 \\
\hline GGT, U/L & $24(6-258)$ & $17(6-32)$ & 0.000 \\
\hline ALP, U/L & $75(41-155)$ & $65(30-111)$ & 0.000 \\
\hline HbA1c, \% & $\begin{array}{c}6.72 \\
(4.71-10.20)\end{array}$ & $\begin{array}{c}4.52 \\
(4.00-5.51)\end{array}$ & 0.000 \\
\hline
\end{tabular}

*Values represent medians (lower-upper quartile).

**Significance of difference in Mann-Whitney test for data following non-normal distributed and t-test for normal distributed data. AST-aspartate aminotransferase; ALT-alanine aminotransferase; GGT-gamma glutamyl transpeptidase; ALPalkaline phosphatase; HbA1c-glycated hemoglobin 
Š. Mandal, Free fatty acids and hepatic activity in Type 2 diabetes, $R A D$ Conf. Proc., vol. 4, 2020, 90-94

Table 2. Composition and concentration of free fatty acids in study populations.

\begin{tabular}{|c|c|c|c|}
\hline Fatty acid & $\begin{array}{l}\text { Cases } \\
\mathrm{N}=71\end{array}$ & $\begin{array}{c}\text { Controls } \\
\mathrm{N}=40\end{array}$ & $\begin{array}{c}p \\
\text { value }^{* * *}\end{array}$ \\
\hline $\begin{array}{l}\text { Myristic acid, C14:0 } \\
\mu \mathrm{mol} / \mathrm{L}\end{array}$ & $\begin{array}{c}2.22 \\
(0.60-10.30) \\
\end{array}$ & $\begin{array}{c}1.73 \\
(0.40-5.00) \\
\end{array}$ & 0.000 \\
\hline $\begin{array}{l}\text { Myristioleic acid, } \\
\text { C14:1 } \mu \mathrm{mol} / \mathrm{L}\end{array}$ & $\begin{array}{c}1.01 \\
(0.40-1.80) \\
\end{array}$ & $\begin{array}{c}1.09 \\
(0.80-2.00) \\
\end{array}$ & 0.000 \\
\hline $\begin{array}{l}\text { Palmitic acid, C16:0 } \\
\mu \mathrm{mol} / \mathrm{L}\end{array}$ & $\begin{array}{c}37.76 \\
(2.40-158.10) \\
\end{array}$ & $\begin{array}{c}28.13 \\
(11.40-57.30) \\
\end{array}$ & 0.000 \\
\hline $\begin{array}{l}\text { Palmitoleic acid, } \\
\text { C16:1 } \mu \mathrm{mol} / \mathrm{L}\end{array}$ & $\begin{array}{c}4.87 \\
(0.90-23.20) \\
\end{array}$ & $\begin{array}{c}3.04 \\
(0.500-6.80) \\
\end{array}$ & 0.000 \\
\hline $\begin{array}{l}\text { Stearic acid, C18:o } \\
\mu \mathrm{mol} / \mathrm{L}\end{array}$ & $\begin{array}{c}9.52 \\
(3.70-37.10) \\
\end{array}$ & $\begin{array}{c}8.99 \\
(4.10-36.40) \\
\end{array}$ & 0.000 \\
\hline $\begin{array}{l}\text { Oleic acid, C18:1 } \\
\mu \mathrm{mol} / \mathrm{L}\end{array}$ & $\begin{array}{c}30.79 \\
(10.70-137.20) \\
\end{array}$ & $\begin{array}{c}23.21 \\
(8.80-42.20) \\
\end{array}$ & 0.000 \\
\hline $\begin{array}{l}\text { Linoleic acid, C18:2 } \\
\mu \mathrm{mol} / \mathrm{L}\end{array}$ & $\begin{array}{c}43 \cdot 35 \\
(16.50-140.90) \\
\end{array}$ & $\begin{array}{c}39.53 \\
(2.50-78.50) \\
\end{array}$ & 0.000 \\
\hline $\begin{array}{l}\text { Y-Linolenic acid, } \\
\text { C18:3 } \mu \mathrm{mol} / \mathrm{L}\end{array}$ & $\begin{array}{c}3.13 \\
(0.60-7.70) \\
\end{array}$ & $\begin{array}{c}1.90 \\
(1.90-1.90) \\
\end{array}$ & 0.185 \\
\hline $\begin{array}{l}\text { Arachidic acid, } \\
\text { C20:0 } \mu \mathrm{mol} / \mathrm{L}\end{array}$ & $\mathrm{LD}^{* * *}$ & $\begin{array}{c}6.90 \\
(6.90-6.90) \\
\end{array}$ & 0.000 \\
\hline $\begin{array}{l}\text { Eicosatrienoic acid, } \\
\text { C20:3 } \mu \mathrm{mol} / \mathrm{L}\end{array}$ & $\begin{array}{c}7.69 \\
(1.60-17.50) \\
\end{array}$ & $\begin{array}{c}7.37 \\
(3.00-14.40) \\
\end{array}$ & 0.000 \\
\hline $\begin{array}{l}\text { Behenic acid, C22:0 } \\
\mu \mathrm{mol} / \mathrm{L}\end{array}$ & $\mathrm{LD}^{* * *}$ & $\begin{array}{c}0.80 \\
(0.80-0.80) \\
\end{array}$ & 0.000 \\
\hline 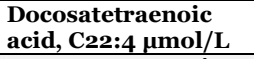 & $\mathrm{LD}^{* * *}$ & $\begin{array}{c}1.08 \\
(0.90-1.30) \\
\end{array}$ & 0.001 \\
\hline $\begin{array}{l}\text { Docosapentaenoic } \\
\text { acid, C22:5 } \mu \mathrm{mol} / \mathrm{L}\end{array}$ & $\mathrm{LD}^{* * *}$ & $\begin{array}{c}1.34 \\
(0.60-2.30) \\
\end{array}$ & 0.013 \\
\hline $\begin{array}{l}\text { Docosaxaenoic acid, } \\
\text { C22:6 } \mu \mathrm{mol} / \mathrm{L}\end{array}$ & $\mathrm{LD}^{* * *}$ & $\begin{array}{c}1.92 \\
(1.00-2.90) \\
\end{array}$ & 0.005 \\
\hline
\end{tabular}

*Values represent medians (lower-upper quartile).

**Significance of difference in Mann-Whitney test for data following non-normal distributed and t-test for normal distributed data.

***LD-limit detection, concentration below of detection limit.

Composition and concentrations of individual FFAs are summarized in Table 2, and there were significantly differ between two groups, except for $\gamma$-linolenic acid $(\gamma-\mathrm{C} 18: 3)$ concentrations [18]. T2D and state of hyperinsulinemia in combination with a high FFA flux as well as hyperglycemia are known to up-regulate lipogenic transcription factors. The fatty acids overload and the hepatic mitochondrial oxidation system leading to accumulation of FFAs in the liver. In the most of cases, liver function in Type 2 diabetes patients contribute alteration of liver enzyme levels i.e. ALT, AST, AP and GGT. Of these liver enzymes, ALT is most closely related to liver fat accumulation and consequently ALT have been used as a marker of fatty liver and its dysfunction [19].

The results of Spearman's analysis showed a positive association between levels of palmitic and stearic acids with ALT activity $(\mathrm{p}<0.05)$, while the activity of GGT was significantly associated with the levels of palmitic, stearic, and oleic acids $(\mathrm{p}<0.01)$. Negative correlation of ALP activity with myristoleic and dihomo- $\gamma$-linolenic acids was observed $(\mathrm{p}<0.05)$. In addition, the one of the main fatty acids in DNL, palmitoleic acid (C16:1) negatively associated with ALT activity but only in controls, while the same fatty acid was negative correlated with ALP in diabetic patients. Interestingly, AST showed no significant association with detected FFAs (Table 3).
Table 3. Spearman's correlation coefficient (rho) between serum free fatty acid concentrations ( $\mu \mathrm{mol} / \mathrm{L})$ and liver enzymes (AST, ALT, GGT, and ALP) in populations.

\begin{tabular}{|c|c|c|c|c|}
\hline FFAzymes & AST & ALT & GGT & ALP \\
\hline C 14:1 & n.d. & n.d. & n.d. & $\begin{array}{c}\mathrm{r}=-0.539 \\
\mathrm{p}=0.026\end{array}$ \\
\hline C 16:0 & n.d. & $\begin{array}{c}\mathrm{r}=0.217 \\
\mathrm{p}=0.021\end{array}$ & $\begin{array}{c}\mathrm{r}=0.196 \\
\mathrm{p}=0.015\end{array}$ & n.d. \\
\hline C 16:1 & n.d. & $\begin{array}{c}\mathrm{r}=0.402 \\
\mathrm{p}=0.034 \\
\text { (only in } \\
\text { controls })\end{array}$ & n.d. & $\begin{array}{c}\mathrm{r}=-0.304 \\
\mathrm{p}=0.025 \\
\text { (only in } \\
\text { cases })\end{array}$ \\
\hline C 18:0 & n.d. & n.d. & $\begin{array}{c}\mathrm{r}=0.213 \\
\mathrm{p}=0.025\end{array}$ & n.d. \\
\hline C 18:1 & n.d. & $\begin{array}{c}\mathrm{r}=0.220 \\
\mathrm{p}=\text { o.o21 }\end{array}$ & $\begin{array}{c}\mathrm{r}=0.220 \\
\mathrm{p}=0.006\end{array}$ & n.d. \\
\hline C 20:3 & n.d. & n.d. & n.d. & $\begin{array}{c}\mathrm{r}=-0.198 \\
\mathrm{p}=0.039\end{array}$ \\
\hline
\end{tabular}

n.d.-not detected

De novo lipogenesis is the primary metabolic pathway involved in the endogenous synthesis of specific fatty acids, such as C16:0, C16:1n-7, C18:0, and C18:1n9, and it is linked to the pathophysiology of many metabolic diseases including incidence of T2D [20]. Chronic hyperglycemia and IR together with hyperinsulinemia cause biochemical reactions that lead to increase in lipogenesis and its associated fatty acid changes. Accumulation of FFAs is known to be toxic to hepatocytes engendering disruption of cell membrane, mitochondrial dysfunction, oxidative stress and increase in production of proinflammatory cytokines [21]. Fat accumulation in hepatocytes lead to liver injury which shown with slightly rise in ALT, AST, and GGT activities, and normal function with or without ALP elevation. These findings consistent and in line with previously researches which confirmed suggested potential pathophysiological and metabolic pathway mechanisms [22, 23].

Recent studies showed that patients with T2D have identified at independent and high risk factor for development of NAFLD. NAFLD is characterized by increased lipids accumulation and fatty infiltration in the liver but still underlying metabolic pathways unknown. Researchers are proposed two possible mechanisms that may explain this chronic metabolic state: i) elevated concentrations of FFA to the liver cause fatty infiltration in the hepatic cells, and ii) increase of DNL as an important source of FFAs and triglycerides in the liver. In present study, although do not performed NAFLD test neither noninvasive nor invasive methods, significant association of elevated ALT, GGT, and ALP especially in cases (Table 3), suggested that Type 2 diabetes patients included in this study have NAFLD [24, 25].

However, the possible explanation of different profile and composition of FFAs and hepatic enzyme activities in serum might be due to influence of gender, age, and ethnicity as well dietary habit and physical activity in study population. 


\section{CONCLUSION}

In summary, obtained data suggest that an elevation of free fatty acid levels and the hepatic fat accumulation in insulin-resistant conditions affect the hepatic enzymes activities, which might contribute further to the progression of Type 2 diabetes and developing of its complications.

\section{REFERENCES}

1. IDF. International Diabetes Federation. IDF Diabetes Atlas - 9th Edition. Diabetes Atlas.

Retrieved from: https://diabetesatlas.org/resources/2017-atlas.html Retrieved on: Sep. 17, 2020

2. P. J. Randle, P. B. Garland, C. N. Hales, E. A. Newsholme, "The glucose fatty-acid cycle its role in insulin sensitivity and the metabolic disturbances of diabetes mellitus," Lancet, vol. 281, no. 7285 , pp. $785-789$, Apr. 1963. https://doi.org/10.1016/s0140-6736(63)91500-9 PMid: 13990765

3. M. Hawkins, J. Tonelli, P. Kishore, D. Stein, E. Ragucci, A. Gitig, K. Reddy, "Contribution of elevated free fatty acid levels to the lack of glucose effectiveness in type 2 diabetes," Diabetes, vol. 52, no. 11, pp. $2748-2758$, Nov. 2003. https://doi.org/10.2337/diabetes.52.11.2748 PMid: 14578293

4. J. A. Menendez, A. Vazquez-Martin, F. Jose Ortega, J. M. Fernandez-Real, "Fatty acid synthase: association with insulin resistance, type 2 diabetes, and cancer," Clin. Chem., vol. 55, no. 3, pp. 425 - 438, Jan. 2009. https://doi.org/10.1373/clinchem.2008.115352 PMid: 19181734

5. S. Jiang, J. L. Young, K. Wang, Y. Qian, L. Cai, "Diabetic induced alterations in hepatic glucose and lipid metabolism: The role of type 1 and type 2 diabetes mellitus," Mol. Med. Rep., vol. 22, no.2, pp. $603-611$, Aug. 2020.

https://doi.org/10.3892/mmr.2020.11175 PMid: 32468027

6. J. Zhang, N. Cheng, Y. Ma, H. Li, Z. Cheng, Y. Yang, et al., "Liver enzymes, fatty liver and type 2 diabetes mellitus in a Jinchang cohort: a prospective study in adults," Can. J. Diabetes, vol. 42, no. 6, pp. 652-658, Dec. 2018.

https://doi.org/10.1016/j.jcjd.2018.02.002 PMid: 29936075

7. S. Nagaraj, S. S. Kiran, R. Gandham, W. D. C. R. Silvia, M. R. Nagaraja, A. S.Nasar, D. Biswajit, "Study of prevalence of non-alcoholic fatty liver disease in type 2 diabetes mellitus patients and variations in liver function tests, lipid profile and mean platelet volume in patients with fatty liver in comparison with patients without fatty liver," Int. J. Res. Med. Sci., vol. 4, no. 3, pp. 871- 876, Mar. 2016.

http://doi.org/10.18203/2320-6012.ijrms20160534 PMid: 603

8. X.-Y. Hu, Y. Li, L.-Q. Li, Y. Zheng, J.-H. Lv, S.-C. Huang, W. Zhang, L. Liu, L. Zhao, Z. Liu, X.-J. Zhao, "Risk factors and biomarkers of nonalcoholic fatty liver disease: an observational crosssectional population survey," BMJ Open, vol. 8, no. 4, pp. 1 - 7, Apr. 2018.

https://doi.org/10.3978/j.issn.2304-3881.2015.01.03 PMid: 29626047
9. H. B. Bhatt, R. J. Smith, "Fatty liver disease in diabetes mellitus," HepatoBiliary Surg. Nutr., vol. 4, no. 2, pp. $101-108$, Apr. 2015.

https://doi.org/10.2337/diabetes.52.11.2748

PMid: 26005676

10. F. Bril, K. Cusi, "Management of nonalcoholic fatty liver disease in patients with type 2 diabetes: A call to action," Diabetes Care, vol. 40, no. 3, pp. 419 - 430, Mar. 2017.

https://doi.org/10.2337/dc16-1787

PMid: 28223446

11. K.L. Donnelly, C. I. Smith, S. J. Schwarzenberg, J. Jessurun, M. D. Boldt, E. J. Parks, "Sources of fatty acids stored in liver and secreted via lipoproteins in patients with nonalcoholic fatty liver disease," J. Clin. Invest., vol. 115, no. 5, pp. 1343 - 1351, May 2005. https://doi.org/10.1172/JCI23621 PMid: 15864352

12. S. Islam, S. Rahman, T. Haque, A. H. Sumon, A. M. Ahmed, N. Ali, "Prevalence of elevated liver enzymes and its association with type 2 diabetes: A cross-sectional study in Bangladeshi adults," Endocrinol. Diabetes Metab., vol. 3, no.2, eoo116, Apr. 2020.

https://doi.org/10.1002/edm2.116

PMid: 32318634

13. D. M. Tanase, E. M. Gosav, C. F. Costea, M. Ciocoiu, C. M. Lacatusu, M. A. Maranduca, A. Ouatu, M. Floria, "The intricate relationship between type 2 diabetes mellitus (T2DM), insulin resistance (IR), and nonalcoholic fatty liver disease (NAFLD)", Journal of Diabetes Research, vol. 2020, Article ID 3920196, p. 16, Aug. 2020. https://doi.org/10.1155/2020/3920196 PMiD: 343446834

14. M. T. Long, S. Gandhi, R. Loomba, "Advances in noninvasive biomarkers for the diagnosis and monitoring of non-alcoholic fatty liver disease", Metabolism, vol. 111, pp. 154259-1-8, Oct. 2020. https://doi.org/10.1016/j.metabol.2020.154259 PMiD: 32387227

15. Association AD. 4, Comprehensive Medical Evaluation and Assessment of Comorbidities: Standards of Medical Care in Diabetes-2019, Diabetes Care, vol. 42 (Suppl 1), pp. S34-S45, 2019. https://doi.org/10.2337/dc19-Soo4

16. American Diabetes Association 2. Classification and Diagnosis of Diabetes: Standards of Medical Care in Diabetes-2018, Diabetes Care, vol. 41 (Suppl 1), pp. S13-S27, 2018.

17. Ethical principles for medical research involving Human Subjects, World Medical Association, Helsinki, Finland, 1964.

Retrieved from: https://www.who.int/bulletin/archives/79(4)373.pdf Retrieved on: Sep. 17, 2020

18. R. Feng, C. Luo, C. Li, S. Du, A. P. Okekunle, Y. Li, Y. Chen, T. Zi, Y. Niu, "Free fatty acids profile among lean, overweight and obese non-alcoholic fatty liver disease patients: a case - control study," Lipids in Health and Disease, vol. 16, no. 165, pp. 1-9, Sep. 2017. https://doi.org/10.1186/s12944-017-0551-1 PMid: 28870233

19. T. Shibabaw, G. Dessie, M. D. Molla, M. F. Zerihun, B. Ayelign, "Assessment of liver marker enzymes and its association with type 2 diabetes mellitus in Northwest Ethiopia," BMC. Res. Notes., vol. 12, no. 707, pp. 1- 5, Oct. 2019.

https://doi.org/10.1186/s13104-019-4742-x

PMid: 204940234 
20. F. Imamura, A. M. Fretts, M. Marklund, A. V. Ardisson Korat, W.-S. Yang, M. Lankinen, et al., "Fatty acids in the de novo lipogenesis pathway and incidence of type 2 diabetes: A pooled analysis of prospective cohort studies," PLoS Med., vol. 17, no. 6, pp. e1003102-1-7, Jun. 2020.

https://doi.org/10.1371/journal. pmed.1003102 PMid: 32530938

21. T. K. Lam, A. Carpentier, G. F. Lewis, G. van de Werve, I. G. Fantus, A. Giacca, "Mechanisms of the free fatty acid-induced increase in hepatic glucose production," Am. J. Physiol. Endocrino. Metab., vol. 284, no. 5, pp. E863-73. May 2003

https://doi.org/10.1152/ajpendo.00033.2003 PMid: 12676648

22. H. R. Ahn, M. H. Shin, H. S. Nam, K.-S. Park, Y.-H. Lee, S.-K. Jeong, "The association between liver enzymes and risk of type 2 diabetes: The Namwon study," Diabetol. Metab. Syndr., vol. 6, no. 1, p. 14, Feb. 2014.

https://doi.org/10.1186/1758-5996-6-14

PMid: 24502834
23. S.-H. Ko, M. K. Baeg, K.-D. Han, S.-H. Ko, Y.-B. Ahn, "Increased liver markers are associated with higher risk of type 2 diabetes," World J. Gastroenterol., vol. 21, no. 24, pp. 7478-87, June 2015. https://doi.org/10.3748/wjg.v21.i24.7478 PMid: 26139993

24. S. Tomah, N. Alkhouri, O Hamdy, "Nonalcoholic fatty liver disease and type 2 diabetes: where do Diabetologists stand?", Clin. Diabetes Endocrinol., vol. 6, no. 9, pp. 1-12, June 2020.

https://doi.org/10.1186/s40842-020-00097-1 PMiD: 32518675

25. M. Akheruzzaman, V. Hegde, A. C. Shin, N. V. Dhurandhar, "Reducing endogenous insulin is linked with protection against hepatic steatosis in mice," Nutr. Diabetes, vol. 10, no. 1, pp. 1-12, Apr. 2020.

https://doi.org/10.1038/s41387-020-0114-9

PMID: 32286259 